\title{
Da teoria crítica ao pós-estruturalismo: breves apontamentos para uma possível confrontação entre Adorno e Deleuze
}

\section{Critical theory and post-structuralism: brief notes for a possible confrontation between Adorno and Deleuze}

\author{
Sinesio Ferraz Bueno ${ }^{1}$
}

\begin{abstract}
RESUMO
A teoria crítica da Escola de Frankfurt e o pós-estruturalismo francês constituem-se em movimentos reflexivos da maior importância na área da filosofia da educação, inspirando inúmeras produções acadêmicas nas últimas décadas. Sendo contemporâneos às décadas de 1950 e 1960, ambos os movimentos apresentam em comum o fato de oporem resistência filosófica a diversos tipos de totalitarismo. Como diferenças mais salientes a ambas correntes de pensamento podemos apontar a crítica da dialética em sua insuficiência como método para refletir sobre a diferença (Deleuze) e a reafirmação da dialética em seus potenciais negativos de confrontação entre o objeto e seu conceito (Adorno). O presente artigo destina-se a refletir brevemente sobre as afinidades temáticas e as diferenças metodológicas entre o pensamento desses dois autores.
\end{abstract}

Palavras-chave: teoria crítica; dialética; filosofia da educação; escola de Frankfurt.

\begin{abstract}
The Frankfurt critical theory and the French post-structuralism are important lines of thought in the philosophy of education, which inspired several academic productions in recent decades. In the 1950s and 1960s, both opposed
\end{abstract}

DOI: $10.1590 / 0104-4060.39699$

1 Universidade Estadual Paulista Júlio de Mesquita Filho, Campus de Marília. Marília, São Paulo, Brasil. Av. Hygino Muzzi Filho, n 737. CEP: 17525-900. Caixa postal: 420. E-mail: sinesioferraz@yahoo.com.br 
philosophical resistance against many types of totalitarianism. One big difference between the two lines of thought has been the critical of the dialectic considered an insufficient method to think about the difference (Deleuze) and the reaffirmation of a negative dialectic (Adorno). This article intends to analyze the thematic affinities and the differences of method between the thought of these two authors.

Keywords: critical theory; dialectic; philosophy of education; Frankfurt school.

Se quisermos apresentar um traço comum entre esses dois movimentos filosóficos do século XX, sem prejuízo de suas imensas diferenças conceituais e interpretativas, poderemos afirmar que a teoria crítica e o pós-estruturalismo originaram-se como reações ao pesadelo kafkiano, que metaforizou a impotência do indivíduo perante o poder anônimo e impiedoso das grandes organizações burocráticas. Dessa forma, seja como reação intelectual aos totalitarismos nazifascista e estalinista à lógica instrumental da empresa capitalista, à colonização unidimensional das sociedades democrático-liberais, às técnicas e práticas de normatização legitimadas pela ciência ou à administração da liberdade exercida pela sociedade de controle, para citar alguns dos grandes temas de que se ocuparam ambas as linhas teóricas, os pensadores alemães e franceses procuraram refletir e compreender o fenômeno da progressiva opressão da vida humana exercida de forma planejada, racional e científica. Tal redução dos dois movimentos ao denominador comum da reflexão sistemática acerca dos fatores históricos e epistemológicos que engendraram os sofrimentos do Sr. K não nos deve, contudo, enganar sobre a grande distância que separou essas duas grades interpretativas da filosofia ocidental. Para os objetivos do presente artigo, as diferenças entre a teoria crítica e o pós-estruturalismo serão enfocadas a partir das posições assumidas por seus respectivos pensadores no que se refere à modalidade de crítica dirigida à racionalidade iluminista. Para esse objetivo, o pressuposto assumido por este trabalho consiste em pensar o caráter interno da crítica dirigida pelos frankfurtianos Adorno, Horkheimer e Marcuse ao esclarecimento, em oposição ao caráter externo da crítica empreendida por Foucault e Deleuze à racionalidade ocidental. Acreditamos que as notáveis diferenças entre os dois movimentos podem ser compreendidas em sua grande parte pela distinção metodológica assumida por essas duas correntes teóricas em sua reflexão sistemática sobre os problemas intrínsecos à razão iluminista. 


\section{Teoria Crítica e autorreflexão da razão}

Em sua Dialética do esclarecimento, Adorno e Horkheimer defrontaram-se com o desafio de explicar por que os filhos da civilização moderna, técnica e racionalizada, apresentam a tendência quase irreversível de regredir a modalidades de pensamento e comportamento místicas, bárbaras e irracionais. A contradição entre o estágio moderno de domínio técnico sobre a natureza, que teoricamente deveria significar uma promessa de liberdade, e a ampliação das mais diversas formas de barbárie no interior da civilização técnica, testemunharam antes o fracasso da razão esclarecida como meio de ampliação da autonomia humana sobre a natureza, do que sua plena realização. Os homens esclarecidos do século $\mathrm{XX}$, potencialmente emancipados da condição primitiva de impotência frente às forças naturais e aos mitos por meio dos quais procuravam precariamente burlar o poder da natureza, não se encontram em condições melhores do que seus antecessores neolíticos, pelo simples motivo de que, na era moderna, os poderes técnicos assumem diante deles a condição análoga de esfera irredutivelmente ameaçadora antes representada pela natureza. Sob o ponto de vista filosófico, o aspecto mais relevante das reflexões dos dois filósofos acerca da articulação sombria entre progresso e regressão que compromete o esclarecimento em sua tarefa primordial de desencantar o mundo é a confiança depositada na capacidade autorreflexiva da razão para compreender e superar seus próprios impasses.

A confiança frankfurtiana nos potenciais autorreflexivos da razão transparece em diversos momentos das obras dos filósofos. No prefácio da Dialética do Esclarecimento, as reflexões sobre a autodestruição da razão são antecedidas pela afirmação de que a regressão somente se tornará um processo irreversível se o esclarecimento não for capaz de acolher dentro de si a reflexão sobre o elemento regressivo. (ADORNO; HORKHEIMER, 1985, p. 13). Analogamente, no prefácio de Minima Moralia, livro de pensamentos dedicados a denunciar o comprometimento da vida humana sob as tendências hegemônicas de administração do público e do privado, Adorno enfatiza, em fidelidade à negatividade hegeliana, que, "hoje, com o desaparecer do sujeito, os aforismos levam a sério a exigência de que 'aquilo mesmo que desaparece' seja 'considerado como essencial"”. (ADORNO, 1992, p. 9). Em Eclipse da razão, obra cujo título implicitamente anuncia a hegemonia da razão instrumental como momento potencialmente superável da história, o prefácio justifica a escrita do livro em função da "capacidade de interpretar com exatidão as profundas mudanças que ora se verificam na mentalidade pública e na natureza humana". (HORKHEIMER, 2002, p. 10). Finalmente, em sua definição lapidar das possibilidades 
intrínsecas do pensamento racional de superar suas próprias aporias, no primeiro parágrafo da Dialética Negativa, Adorno expressa a capacidade autorreflexiva da razão no momento histórico que testemunha o fracasso de suas promessas de emancipação: "a filosofia, que um dia pareceu ultrapassada, mantém-se viva porque se perdeu o momento de sua realização". (ADORNO, 2009, p. 11). Acima de tudo, o que é comum a todas essas referências ao estatuto substantivo da razão para pensar suas próprias contradições é a persistência dos pensadores da teoria crítica na suficiência do pensamento dialético para empreender a tarefa de autorreflexão exigida na modernidade. Sob esse aspecto, Adorno enfatiza a negatividade da dialética como "consciência consequente da não-identidade", como pensamento capaz de ultrapassar a si mesmo ao chocar-se contra seus limites. (ADORNO, 2009, p. 13). No que se refere à sua distinção frente às vertentes filosóficas do pós-estruturalismo, conforme será especificado adiante, a teoria crítica, ao reconhecer a insuficiência do princípio de identidade para representar adequadamente o objeto em suas singularidades e diferenças específicas, salienta, contudo, a qualidade do método dialético de diferenciar o objeto na mesma medida em que o subsume sob categorias conceituais: "a identidade não desaparece por meio de sua crítica; ela se transforma qualitativamente". (ADORNO, 2009, p. 130). Notadamente para Adorno, a dialética, em sua essencialidade negativa, é instrumento suficiente para a tarefa autorreflexiva, uma vez que, ao assumir suas limitações no processo de denominar adequadamente a identidade do objeto mediante conceitos identificadores, ela é igualmente capaz de integrar, compreender e superar suas próprias insuficiências, uma vez que "a consciência da não-identidade contém a identidade”. (ADORNO, 2009, p. 130).

\section{Antifundacionalismo em Deleuze}

Uma síntese adequada sobre os pontos comuns que unem os pós-estruturalistas franceses no âmbito filosófico é apresentada por Michael Peters, situando tal movimento como crítica "às diversas construções filosóficas do sujeito: o sujeito cartesiano-kantiano, o sujeito hegeliano e fenomenológico; o sujeito do existencialismo, o sujeito coletivo marxista". (PETERS, 2000, p. 31). De fato, em seu estilo não usual de mobilização das categorias filosóficas, o pós-estruturalismo, ao contrário da teoria crítica, reagiu ao pesadelo kafkiano mediante a realização de uma crítica radical aos próprios alicerces do esclarecimento. Nesse sentido, o trabalho de Foucault pode ser caracterizado como uma tendência fortemente sobrecarregada de historicização da ontologia, e o trabalho 
de Deleuze como uma ontologia do devir acentuadamente antidialética. Assim, ao menos sob essas duas perspectivas, a filosofia pós-estruturalista descortina-se como crítica radical das diversas formas de concepção transcendente do sujeito e da própria realidade. Mais especificamente no caso da filosofia de Deleuze, esta se apresenta como uma "ontologia não-metafísica", "refratária à constituição do ser aos pressupostos que foram construídos pelo legado platônico-aristotélico". (VASCONCELLOS, 2005, p. 141).

O caráter acentuadamente antifundacionalista do pós-estruturalismo está nitidamente presente no conjunto da obra de Deleuze, em especial em Diferença e repetição, livro no qual o filósofo francês realiza sua crítica a todas as formas de representação e identidade. Na crítica a Platão, sob forte inspiração nietzschiana, o filósofo francês questiona as pretensões fundantes da metafísica em sua divisão original do real como oposição entre um mundo inteligível das ideias, entendidas como modelos ou paradigmas perfeitos dos objetos, e o mundo sensível e empírico, reduzido a universo de cópias imperfeitas ou simulacros dos seres. A primazia platônica atribuída ao caráter ontológico do mundo das ideias significa, para Deleuze, o privilégio a mediações conceituais representativas que, ao estabelecerem o primado da ideia, negligenciam o caráter multiforme, caótico e irredutível das diferenças reais, cuja natureza é impermeável a representações conceituais. Contra o platonismo, Deleuze enfatiza a necessidade de sua reversão crítica, de tal forma que as diferenças puras, pensadas em si mesmas sem o auxílio precário das mediações representativas, refletidas sob a forma de simulacros, anteriormente depreciados por Platão, passem a ter a primazia em uma ontologia do devir caracterizada pela eterna repetição da diferença. A ênfase crítica do antifundacionalismo de Deleuze é igualmente dirigida à dialética hegeliana, justamente porque esta teria realizado uma gigantesca ilusão de ótica, que consistiria em sua pretensão de abrigar a diferença sob o primado da negação e da contradição: "a audácia hegeliana é a última e a mais poderosa homenagem prestada ao velho princípio". (DELEUZE, 2000, p. 58). No prólogo de Diferença e repetição, Deleuze explicita sua batalha filosófica por uma filosofia da diferença ontológica: "queremos pensar a diferença em si mesma e a relação do diferente com o diferente, independentemente das formas da representação que as conduzem ao Mesmo e as fazem passar pelo negativo". (DELEUZE, 2000, p. 8). Sob esse aspecto, ao menos em princípio, não poderia haver maior contraste entre o pós-estruturalismo deleuziano e o conjunto dos filósofos da teoria Crítica, em especial no que se refere a Adorno, Horkheimer e Marcuse. A crítica de Deleuze ao hegelianismo inicia-se pela refutação das pretensões fundantes da tríade dialética, argumentando que a mediação negativa, que remete a tese à sua suposta antítese, posteriormente reconfigurada afirmativamente como síntese, implica apenas a postulação de 
uma epifenomenologia que em seu efeito de ilusão de ótica nada mais faz do que simplesmente trair e desnaturar a diferença em seu estado puro. Para Deleuze, a "diferença é o verdadeiro conteúdo da tese, a obstinação da tese", cuja singularidade irredutível recusa toda subsunção a mediações representativas conceituais, inclusive as dialéticas, cuja natureza consiste em reafirmar, ainda que por meio da negação, o caráter fundante do princípio de identidade como representação. (DELEUZE, 2000, p. 60). Quando assumem maior explicitude discursiva, os exageros do discurso deleuziano são didáticos para expressar suas restrições radicais à dialética hegeliana. Afirma o filósofo que "as formas segundo as quais a 'coisa nega o que ele não é' ou 'se distingue de tudo o que ela não é', são monstros lógicos [...] a serviço da identidade". (DELEUZE, 2000, p. 58). A negação da identidade estabelecida dos objetos reais, por meio de sua mediação negativa e conceitual, que supostamente apresentaria o mérito de potencializar a diferença, acarreta apenas o efeito de inscrevê-la na "circulação infinita do idêntico através da negatividade". (DELEUZE, 2000, p. 58). Subordinando a diferença à identidade, aprisionando-a na "similitude e na analogia", a dialética de Hegel, segundo Deleuze, repete o equívoco antes cometido pelo "olho grego do justo meio", confusão que ele considera danosa para a filosofia da diferença: "confundir o conceito próprio da diferença com a inscrição da diferença na identidade do conceito em geral". (DELEUZE, 2000, p. 58).

\section{Teoria Crítica e pós-estruturalismo: afinidades temáticas}

A ênfase de Deleuze acerca da diferença como princípio irredutível de uma ontologia do devir justifica-se, conforme afirmamos na primeira parte do presente trabalho, como reação ao que genericamente propomos ter sido o pesadelo kafkiano, que igualmente motivou os principais trabalhos da teoria crítica. Nesse sentido, em sua reação às diversas tendências totalitárias que afetaram a modernidade, é importante notar que, embora alicerçada em fundamentos dialéticos, a crítica de Adorno e Horkheimer ao progresso científico na Dialética do Esclarecimento permite o apontamento de nítidas afinidades temáticas com a filosofia da diferença.

Em sua obra comum, Adorno e Horkheimer caracterizaram a essência totalitária do esclarecimento pela primazia que este atribui, notadamente desde o patriarcalismo epistemológico baconiano, aos procedimentos instrumentais de cálculo e ao princípio utilitário no domínio da natureza. O totalitarismo da razão manifesta-se em sua forma mais acabada e brutal sob a égide da ciência positi- 
vista, que intenta subsumir cartesianamente todo o mundo natural e igualmente o mundo humano à categoria da identidade. Como "radicalização da angústia mítica", vale dizer, como expressão moderna do medo e impotência do homem frente às forças naturais, o positivismo recalca toda diferença que não possa ser acomodada em suas grades mensurabilizantes, anulando previamente todas as qualidades que em linguagem deleuziana podem ser traduzidas como "diferenças puras". O aspecto totalitário dessa forma patriarcal de conhecer o mundo para dominá-lo busca eliminar toda alteridade possível, uma vez que "nada mais pode ficar de fora, porque a simples ideia do 'fora' é a verdadeira fonte da angústia”. (ADORNO; HORKHEIMER, 1985, p. 29). O totalitarismo da razão esclarecida desencadeia pelo menos duas consequências graves analisadas pelos filósofos da teoria crítica. Em primeiro lugar, sob o imperativo da eliminação do incomensurável, não somente as qualidades e diferenças são dissolvidas pelo pensamento identificante, como também os próprios homens são forçados à equivalência ditada pelo valor de troca no mercado. Embora tal indiferença seja acompanhada por indiscutíveis potenciais de liberdade no que se refere à não discriminação das pessoas em razão de sua origem social, o preço dessa vantagem "é pago por elas mesmas ao deixarem que suas propriedades inatas [e, portanto, suas diferenças] sejam modeladas pela produção das mercadorias que se podem comprar no mercado". (ADORNO; HORKHEIMER, 1985, p. 27). A anulação da diferença pelo primado da identidade adquirida no mercado explicita a afinidade entre a crítica frankfurtiana ao esclarecimento e a crítica deleuziana ao paradigma da representação: "os homens receberam o seu eu como algo pertencente a cada um, diferente de todos os outros, para que ele possa com tanto maior segurança se tornar igual". (ADORNO; HORKHEIMER, 1985, p. 27). Em segundo lugar, diante do progresso técnico e científico, presidido pela epistemologia cartesiana e positivista, todas as diferenças, tudo "o que não se submete ao critério da calculabilidade e da utilidade torna-se suspeito para o esclarecimento". (ADORNO; HORKHEIMER, 1985, p. 21). Isso significa, em linguagem dialético-materialista, que o próprio pensamento torna-se reificado e alheio à única possibilidade de correção vislumbrada pelos teóricos-críticos, a saber, a autorreflexão. $\mathrm{O}$ esclarecimento, condicionado pelos imperativos do cálculo e da utilidade, regride ao estágio mítico que seu princípio intrínseco de desencantamento do mundo tinha por objetivo superar. Como resultado do entrelaçamento da razão com o mito, o positivismo científico expande as potências de superação da impotência humana diante da natureza, porém agora mantendo os homens sob o jugo de uma racionalização devastadora que desconhece limites éticos para sua expansão. Como resultado, identicamente ao ciclo mítico do eterno retorno, a racionalidade instrumental condena-se à repetição do mesmo que recalca a diferença, subsumindo-a à representação conceitual positivista. A 
repetição do mesmo, que em linguagem deleuziana expressa o encarceramento da diferença sob o jugo da identidade e da representação, é caracterizada por Adorno e Horkheimer como perversão dos objetivos da razão de dominar o mundo para libertar os homens, em um processo no qual "até mesmo aquilo que não se deixa compreender, a indissolubilidade e a irracionalidade, é cercado por teoremas matemáticos". (ADORNO; HORKHEIMER, 1985, p. 37).

\section{Dialética negativa e a priorização da não identidade}

Em termos gerais é possível dizer que a crítica de Deleuze à subsunção de entidades reais (coisas materiais, pessoas, culturas, etc.) a representações conceituais abstratas aproxima-se da crítica frankfurtiana à hegemonia do positivismo e da teoria tradicional no campo do conhecimento científico. Essa proximidade não deve ser recebida com surpresa, uma vez que o movimento pós-estruturalista e a teoria crítica desenvolveram-se durante períodos históricos muito próximos, configurando-se como reação filosófica a um conjunto de processos de natureza totalitária, aqui sintetizados como "pesadelo kafkiano" do século XX. Opondo-se de maneira radical às tendências de anulação das singularidades dos objetos reais a representações conceituais aspiradoras de universalidade suspeita, tanto Deleuze quanto Adorno podem ser considerados como pensadores mutuamente engajados na defesa da primazia do objeto e da diferença contra as mais diversas abstrações conceituais: a fórmula matemática, a ciência positivista, o partido político, etc. Considerando-se essa natureza comum a ambos os movimentos filosóficos, o ponto em que ambos os pensadores se afastam, igualmente de maneira radical, reside no emprego da dialética como método de pensamento capaz de preservar a diferença e a singularidade dos objetos reais em sua confrontação com a universalidade. O pensamento de Deleuze recusou incisivamente qualquer possibilidade de pensar a diferença com integridade no interior dos quadros da mediação negativa do objeto (considerando, inclusive, o mero emprego do termo "objeto" já sendo resultado do enquadramento coercitivo da representação), enquanto o pensamento de Adorno permaneceu fiel à consistência do método dialético como recurso capaz de preservar as possíveis afinidades entre o objeto e seu conceito. Sob o ponto de vista da teoria do conhecimento, tudo indica que as dissonâncias entre os dois pensadores sobre a dialética resultam de perspectivas muito distintas no que se refere ao lugar da identidade conceitual como fundamento para o pensamento. No âmbito deleuziano, a simples subsunção de uma entidade real ao conceito, seu enquadramento forçado a uma representação 
que a qualifica como objeto dotado de uma identidade, implica de antemão uma atitude de negligência a diferenças puras irredutivelmente rebeldes ao pensamento conceitual. Nesse sentido, a crítica de Deleuze expressa uma recusa radical de toda a identidade como alicerce para o pensamento sobre a realidade. Para o filósofo francês, diante desse embate entre as diferenças e a camisa de força da identidade, restaria apenas a possibilidade de um pensamento que seja capaz de produzir conceitos filosóficos despidos das pretensões representacionais e universalistas, remetidos não mais a fundamentos essencialistas, mas a um plano de imanência pré-filosófico, implicado por uma "experimentação tateante", por "meios pouco racionais e razoáveis", associados à "ordem do sonho, dos processos patológicos, das experiências razoáveis, da embriaguez e do excesso". (DELEUZE; GUATARI, 1992, p. 58).

Não pretendemos nos alongar na descrição dos labirintos rizomáticos e propositadamente enigmáticos e imprecisos da filosofia de Deleuze em suas pretensões de apresentar-se como caminho viável para um pensamento capaz de preservar a integridade da diferença em estado puro. Para nos mantermos nos limites estabelecidos para este artigo, basta explicitar uma vez mais o principal motivo que levou Deleuze à sua impiedosa crítica de matriz nietzschiana a mais de vinte séculos de metafísica ocidental: a pretensão dos conceitos abstratos e transcendentes de corresponderem realisticamente às entidades do mundo sensível. Curiosamente, se, em Diferença e repetição, Deleuze enfatiza sua intenção declarada de implodir o paradigma metafísico fundamentado na identidade e na representação, Adorno, em sua Dialética Negativa, explicita a insuficiência dos conceitos dialéticos para se estabelecerem congruentemente em relação aos objetos que pretendem representar. Ambos os pensadores examinam em suas obras o mesmo problema, a saber, a insuficiência da identidade, da representação e do pensamento conceitual para representar com fidelidade a singularidade do objeto particular. A distinção entre os dois pensadores reside no fato de que, enquanto Deleuze recusa a dialética, denunciando sua insuficiência, Adorno prioriza o momento negativo de não identidade para potencializar a autorreflexão da dialética sobre sua irredutível fraqueza, de maneira a preservar a tensão entre o objeto e seu conceito. Ao passo que Deleuze envereda pela recusa rizomática da identidade, propondo uma elaboração conceitual não transcendental, referida à criação de conceitos simultaneamente absolutos e relativos, mergulhados no plano de imanência, Adorno igualmente recusa a transcendência conceitual em virtude da autarquia ilusória e nefasta que ela sugere ao pretender identificar as coisas e seus conceitos. Contra a transcendência, Adorno defende uma crítica imanente comprometida com o conteúdo de verdade do objeto à luz de sua relação com a totalidade. Sua dialética negativa suspende o momento da síntese para preservar a tensão entre coisas e seus conceitos, explicitando um estado 
de não identidade que preserva as ideias como signos negativos que existem no espaço entre o que as coisas pretendem ser e o que efetivamente são. Ao suspender o momento de síntese da dialética, implodindo as pretensões autárquicas do pensamento que pretendem estabelecer a união feliz entre as coisas e seus conceitos, Adorno involuntariamente aproxima-se da busca deleuziana pelas diferenças puras: "a não-verdade de toda identidade obtida é a figura invertida da verdade; [...] o singular é mais e menos do que a sua determinação universal". (ADORNO, 2009, p. 131-132).

Entretanto, seria intelectualmente leviano desconsiderar não apenas a distância entre os dois pensadores, como também a superioridade da dialética negativa em sua capacidade de responder de forma consistente às objeções postas pela filosofia da diferença. Seguindo a chave de leitura de Adorno, podemos compreender a crítica deleuziana às mediações conceituais representativas, justificadas por sua propriedade de aniquilamento das qualidades caóticas e irredutíveis das diferenças reais, como objeção que em si mesma é mediada pelo pensamento identitário. De acordo com a notável lucidez de Peter Dews, "a afirmação ontológica de uma pluralidade irredutível" das alteridades, heterogeneidades e diferenças que caracterizaram fortemente o pós-estruturalismo é inseparável de diversos aspectos problemáticos. (DEWS, 1996, p. 56). Um dos principais diz respeito ao dilema originalmente nietszcheano entre uma posição crítica à tendência da mente humana de reduzir o caos e a diversidade à simplificação conceitual, e, por outro lado, sua justificativa pragmática desse nivelamento, que ocorreria em nome da necessidade de sobrevivência da espécie humana, para a qual a autoconservação seria impossível sem a segurança intelectual dos conceitos. (DEWS, 1996, p. 56). A resposta da teoria crítica é precisamente resumida por Dews: "a tese de Adorno é que a pura singularidade é em si uma abstração, o resíduo do pensamento identificatório". (DEWS, 1996, p. 61). A primazia das diferenças puras enfatizada por Deleuze, em sua pretensão de concretude do imediato, é simples efeito reverso e mediado pelas pretensões totalitárias do pensamento conceitual. Em outras palavras, o percurso antirrepresentacional e anti-identitário realizado por Deleuze em nome da pureza da diferença somente pode ser compreendido não como um trabalho filosófico originalmente espontâneo e não mediado de libertação da riqueza do singular, mas, antes, como efeito reflexo do insucesso necessário de enquadrar o não idêntico sob a armadura conceitual. Não é por acaso que a filosofia da diferença não opera primeiramente pela evocação do singular, em sua suposta riqueza incomensurável, mas antes, pela desqualificação do platonismo e do hegelianismo, que são eleitos como representantes privilegiados do rolo compressor da representação e da identidade. Nesse sentido, a persistência romântica do pensador francês de deslocar a culpa da coisa para o método parece 
ser bem menos produtiva do que a atitude filosófica que, diante da constatação do caráter totalitário das pretensões autárquicas do pensamento, em vez de conformar-se perante o que parecem ser os limites irredutíveis do intelecto, conduz a contradição a desdobrar-se sobre si mesma, movida pelo esforço de sua superação. $\mathrm{O}$ fracasso necessário da identidade conceitual não deveria ser pretexto para escapismos românticos de captura das diferenças puras, pois isso implica negligenciar não apenas as suas próprias mediações intrínsecas, como também a potencialidade da razão de chocar-se contra seus próprios limites, integrá-los e superá-los como "consciência consequente da não-identidade". (ADORNO, 2009, p. 13). A favor do pensamento dialético evidencia-se o fato de que as diferenciações e dissonâncias do singular somente são mobilizadas contra o pensamento conceitual a partir do momento em que este procura impor sua frustrada pretensão de totalidade aos objetos da experiência cognoscente. Permanecendo tributária dessa insuficiência, que é precipitadamente assumida como limite irredutível da razão, a filosofia da diferença, assim como o pós-estruturalismo em suas linhas gerais, trai seu caráter mediado apontado por Adorno, não somente pelas armadilhas que são inerentes a toda a crítica dirigida à universalidade, como também em virtude de seu "autodesprezo reativo à autonomia do espírito". (ADORNO, 2009, p. 39).

\section{Conclusão}

Como conclusão a esta breve problematização entre a crítica antiessencialista de Deleuze e a dialética negativa de Adorno, cabe esclarecer de maneira sintética dois motivos que fazem da dialética um modelo mais produtivo quando comparada com a filosofia da diferença deleuziana. O primeiro deles refere-se à maior consistência apresentada pelo pensamento de Adorno no que se refere aos limites da razão para pensar objetos sem mobilizar os procedimentos de identidade e de representação. Em outras palavras, o empreendimento deleuziano pode envolver-se em sérias dificuldades caso seja constrangido a responder a uma pergunta muito simples: é possível pensar sem representar e sem identificar, vale dizer, sem subsumir objetos reais a conceitos universais, mesmo que provisoriamente? Embora horizontes não representativos e não identificatórios possam ser sugeridos, serão eles possíveis ou viáveis para a consciência humana? A pergunta fica no ar, carente de uma resposta consistente a ser dada pelos pós-estruturalistas contemporâneos simpáticos ao pensamento de Deleuze. Por outro lado, a dialética negativa adorniana permite que tal pergunta seja respondida 
sem vacilações, pois o princípio de identidade é intrínseco a todo esforço da consciência: "toda determinação é identificação. Secretamente, a não-identidade é o telos da identificação, aquilo que precisa ser salvo nela; o erro do pensamento tradicional é tomar a identidade por sua finalidade". (ADORNO, 2009, p. 130). O segundo motivo pode ser exposto por uma interrogação proporcionalmente trivial à primeira: sem o recurso a conceitos universais, que possam remeter a princípios mínimos de dignidade passíveis de serem estendidos a toda a humanidade, como será possível formular juízos críticos e eventualmente condenatórios frente a práticas culturais ou individuais, que em sua prosaica diferença e singularidade, corroboram a violência e a barbárie? Se dermos primazia a diferenças puras, imaculadamente preservadas e livres das prisões conceituais, não teremos sequer condições de definir o que são "violência" e "barbárie", e nem mesmo aquilo que nossas habituais representações costumam definir como seu oposto, a "civilidade". A ausência de parâmetros conceituais que permitam medir a distância de determinadas condições de vida em relação a estados razoavelmente desejáveis de humanidade e de civilidade apresentam o sério risco de tornar os homens reféns de um relativismo ético irracional e indesejável. Esta segunda pergunta pode ser respondida sem constrangimentos pela teoria crítica em sua versão dialeticamente negativa, pois "na repreensão pelo fato de a coisa não ser idêntica ao conceito também vive a nostalgia própria a este último de que ela poderia se tornar idêntica". (ADORNO, 2009, p. 130). Do lado do pós-estruturalismo, um estudioso abordou essa questão salientando que, embora recuse a idealização de utopias e estados prometidos de reconciliação universal, nem por isso esse movimento filosófico recai em mera resignação política indiferente à necessidade de práticas de resistência. Lembrando conhecidas atitudes ativistas de Deleuze e de Foucault a favor dos direitos humanos dos presidiários franceses, e coerentemente com sua filosofia antiuniversalista, "o pós-estruturalismo envolve uma crítica da política utópica e uma reflexão sobre como manter o desejo por um mundo melhor sem uma imagem fixa do que este mundo deveria ser". (WILLIANS, 2012, p. 41, itálico no original). Mas, no reino das diferenças puras, como definir o que poderá ser um "mundo melhor"?

\section{REFERÊNCIAS}

ADORNO, T. W.; HORKHEIMER, M. Dialética do Esclarecimento. Rio de Janeiro: Zahar, 1985. 
ADORNO, T. W. Dialética Negativa. Rio de Janeiro: Zahar, 2009.

ADORNO, T. W. Minima Moralia. São Paulo: Ática, 1992.

DELEUZE, G. Diferença e repetição. São Paulo: Relógio D’água, 2000.

DELEUZE, G.; GUATARI, F. O que é a filosofia? São Paulo: Ed. 34, 1992.

DEWS, P. A. Pós-estruturalismo e a crítica da identidade. In: ZIZEK, S. Um mapa da ideologia. Rio de Janeiro: Contraponto, 1996.

HORKHEIMER, M. Eclipse da razão. São Paulo: Centauro, 2002.

PETERS, M. Pós-estruturalismo e filosofia da diferença. Belo Horizonte: Autêntica, 2000.

VASCONCELLOS, J. A ontologia do devir de Gillez Deleuze. Fortaleza: Kalagatos, 2005. v. 2, n. 4.

WILLIAMS, J. Pós-estruturalismo. São Paulo: Vozes, 2012.

Texto recebido em 30 de janeiro de 2015.

Texto aprovado em 09 de junho de 2015. 
